\title{
A PRACTITIONER'S VIEW OF HUMAN-COMPUTER INTERACTION RESEARCH AND PRACTICE
}

by Sabine Geld of \& Joannes Vandermeulen, Namahn, Brussels

\begin{abstract}
Namahn, a Belgian User Centered Design consultancy, describes the approach it took in radically renewing its methods and techniques to tackle interaction design for critical systems. At the heart of its effort, lies the tension between research and practice and the challenge of transforming research findings into a market-worthy methodology. Namahn chose an inherently distributed approach, grounded in the company's experience, using the appropriate communication tools. The article describes a twoyear project for the regional government's research and innovation program. During the first phase of the project, Namahn discovered a number of important new concepts and methodological hypotheses. These concepts, which grew out of a review of the research literature on models, theories, and frameworks in Human-Computer Interaction, are becoming part of Namahn's extended vocabulary, aimed at enhancing the company's internal communication about the design process. The initial methodological hypotheses on risk assessment and design rationale form the basis of its new methodology, which will be constructed in a bottom-up fashion based on case studies in the project's second phase. Namahn presents concerns and opens issues that arose during the project, which it is exploring as a way to go forward in integrating research findings into the practice of user-centered design (UCD).
\end{abstract}

Keywords: best practices, consultancy, critical systems, theory, user-centered design (UCD)

In this work, Namahn, a Brussels-based usercentered design consultancy, introduces the practical challenges we face in building the bridge from scientific research to effective methodologies for developing critical systems. We then briefly profile our company and outline the theories shaping our two-pronged, longterm strategy to become experts in critical systems design and to create a design approach deeply rooted in research. To frame our market strategy, the company is undertaking a twoyear research project for the Brussels regional government's research and innovation program. An overview of our findings as we achieved the project's first milestone is then provided.
Finally, we look at what remains to be done and discuss a number of issues that emerged during the project.

\section{BRIDGING RESEARCH AND PRACTICE}

Integrating research into the practice of humancomputer interaction ( $\mathrm{HCl}$ ) poses a number of challenges for a consultancy. First, there is a broad gap between theory and practice. Researchers investigating the relationship of human action and thought while using computers come up with interesting findings, but they rarely have a direct impact on the practice of interaction design. Moreover, these theories tend to be elaborate and hard to grasp. Second, more theory does not necessarily lead to more business! When a company has established a solid practice it is not obvious how integrating more theory leads to higher profits, certainly not in the short term. Applying research findings to practice often requires expending considerable effort on elaborate analyses and complex design processes, which can prove a hard sell.

Indeed, in our domain, a consultancy's practice is rarely grounded in research methods since the imperative of quickly bringing a product to market favours the approach of borrowing practical guidelines without investigating the theoretical background. Thus, Namahn's decision to make research methods integral to the company's activity represents a mature consultancy's move to include new information where barriers to market entry are higher.

When Namahn was founded in 1987, our disciplines were human-factors engineering and user-support materials. While designing user interfaces was our preferred practice area, developing user manuals was the cash cow. At the time, the importance of user-centred design (UCD) was poorly understood and it took major marketing efforts to convince our customers of its value. Today, Namahn is known as a leader in the UCD field, with its practice grounded in three disciplines: requirements engineering, interaction design, and information architecture. Our 15 designers serve producers of digital products, whose product users are consumers, knowledge workers, and technical operators. 
Currently, Namahn has reached a comfortable level of profitability, and established a reputation in both the client and labour markets. We have built valuable relationships with the $\mathrm{HCl}$ academic community, as well as with practitioners, and have evolved into a mature company that handles highly complex projects. However, as the perceived value of UCD has risen, so has the number of service providers.

It was in this context that Namahn took a hard look at its strategic direction and decided to become even more specialized, using a deepening specialization as our engine for growth. We adopted what is known as the hedgehog principle (Collins, 2001). In Isaiah Berlin's essay The hedgehog and the fox, "the fox knows many things but the hedgehog knows one big thin. The clever fox will use many tactics to beat the hedgehog but the hedgehog usually wins by following his one simple strategy when threatened - curl up in a ball.

\section{BACK TO THE FUTURE TO ACHIEVE A COMPETITIVE EDGE}

The lesson Collins offers to business is that to define your hedgehog principle, in other words your focus, you need to answer three questions:

1. What passion motivates you in your business or compels you to do what you do?

2. What is your claim to fame? In other words, what are the capabilities you have or know you can create that will separate you from the pack?

3. What drives profitability for your company?

Namahn chose to respond to competitive pressure by adopting a contrarian strategy (Kim \& Mauborgne, 2005). That is, while others are increasingly designing for consumer users, Namahn is turning its focus to technical operators as users. We are going back to the future, as we say, by returning to the roots of the human factors and ergonomics disciplines.

In order to successfully serve safety-critical markets, however, a design consultancy must master pertinent methods grounded in proven theory, since design risks in this field are not an option. Therefore, with our long-term market strategy in mind, Namahn submitted a research proposal to the Brussels regional government's research and innovation program (IWOIB/IRSIB). The proposal was accepted and our two-year research project is the focus of this article.

\section{BECOMING THE GO-TO COMPANY FOR CRITICAL SYSTEMS DESIGN}

Our long-term strategy moves Namahn in an important direction: designing safety-critical systems with research as part of our practice. By focusing on this one area, backed by valid and reliable research, we aim to become the go-to company for critical-systems interaction design.

Critical systems have stringent requirements in terms of error avoidance, efficiency, and risk management. Performance errors are serious because of their enormous impact on human health, the environment, or financial results. Typical applications are: aviation control, nuclear power plant management, medical applications, and trading tools. To design for these types of systems, Namahn needs to acquire specialist knowledge, techniques, and expertise. Additionally, design decisions need to be traceable and rooted in research findings.

As knowledge and innovation are key to Namahn's competitive advantage, it follows that research must be integral to our activity. This involves a continual and explicit investment in acquiring and developing knowledge in the interaction design arena. Our goal is not only to deliver good designs, but also to be able to explain why we make particular design decisions. We want to move from a commonsense, reflexive approach to one that is informed by conscious thinking. By implementing these changes, we are moving from a design consultancy to a design and research consultancy.

In overviews of interaction design by Rogers (2004) and Carroll (2003) the field is portrayed as broad, multidisciplinary and rapidly expanding. Rogers explores the relationship between $\mathrm{HCl}$ theory and practice and provides a number of reasons for theory's limited impact on $\mathrm{HCl}$ practice: it is difficult to choose from the broad offerings available, expectations in the professional community are too high (theory can only indirectly influence practice), and an investment in research is too costly in terms of time, effort, and skills. Rogers's recommendations include improving communication between researchers and designers through the use of a lingua franca. From another perspective, Carroll provides an overview of the different $\mathrm{HCl}$ Models, Theories and Frameworks (MTFs). From Carroll, we selected the MTFs or topics we believed were most relevant to critical systems.

Our approach in this innovation project takes the tension between theory and practice as a starting point. We try to tackle this tension through a distributed, three-step approach.

\section{THE DISTRIBUTED APPROACH}

To avoid a situation in which a few researchers in the company acquire the knowledge and must share it with the practitioners, we deliberately opted for a distributed 
effort. Every designer takes part in the innovation project and becomes the owner of a particular MTFor topic. He or she investigates the topic, becoming its advocate when it comes to applying research to practice.

A distributed effort implies communication mechanisms, so that the knowledge is shared as broadly as possible. We use a wiki to this effect. Additionally, short plenary sessions are held to notify other designers of important updates to the wiki. We also set up a regular off-site to focus on the project, encourage collaboration, and share knowledge.

\section{HYPOTHESIS - VALIDATION - CONSOLIDATION}

Our major goal concerns acquiring knowledge about MTFs that is useful in interaction design for critical systems, and translating that knowledge into practiceoriented and market-worthy methods. To this end, we adopted a three-step process.

\section{Step 1: Generate hypotheses}

Every topic owner explores the literature and distills hypotheses regarding the applicability of ideas. These hypotheses address the question, "How could we use this theoretical knowledge when designing for critical systems?" The criteria for retaining concepts and approaches from the research literature are:

1. Is the concept crucial to critical systems?

2. Does the concept have concrete implications for design?

The consultants rely on their professional experience to determine the relevance of the theoretical knowledge to the interaction design process.

\section{Step 2: Validate hypotheses}

Moving from theory to practice, we will test the value and our understanding of the hypotheses in case studies within client-like organizations. These are non-commercial projects in our target domain of critical systems. These organizations are aware that Namahn is looking ahead to future developments rather than solving pressing needs and that, given the project's research nature, we cannot guarantee a successful outcome.

\section{Step 3: Consolidate findings}

The lessons learned from the validation step will be integrated into a coherent methodology for the design of interfaces to critical systems. We deliberately decided not to use our current methodology unaltered as a starting point, and instead decided to synthesize a radically new methodology, bottom up, from the various methodology components emerging from the case studies.
By using this approach, we aim to bridge theory and practice. When reviewing the research literature, we focus on findings that will help us to improve our design approach, bearing in mind that our hypotheses need to be validated in real-world case studies. On the other hand, given our aim to synthesize a radically new methodology that is relevant for practice, we look for novel ideas and concepts based in the research literature, which we present later in this article.

Concurrently, we identified three other activities crucial to the challenge of bridging the gap between theory and practice, and specific to critical systems. First, we concern ourselves with the ontology of critical systems or their essence.We needed to ask ourselves what issues we have to tackle.We considered how UCD for critical systems differs from UCD in general, and asked ourselves if that broad term is still an appropriate term to designate our work. Second, we developed a lingua franca that is instrumental in bridging the gap between theory and practice. This had to be an adequate vocabulary that would enhance both our reasoning and communication about the interaction design process. Our vocabulary will consist of two types of elements:

1. Abstract terms identifying features and interface parameters. The Cognitive Dimensions framework of Green and Blackwell (1998) is a good starting point, because it makes explicit trade-offs in the design process.

2. Concrete design patterns identifying building blocks for interface design. Ideally they can be linked to the issues and trade-offs within the abstract terms.

Finally, we developed a design rationale, since a systematic and methodological approach to documenting design decisions is paramount to critical systems. In the research literature, the topic of design rationale concerns itself with identifying tools and methodologies. An in-depth study of these two concerns helped us determine a viable and cost-effective approach.

As shown in Figure 1 the ontology extends over the entire project. Our lingua franca and design rationale will be subject to the threestep hypothesis, validation, and consolidation approach just discussed, and together, these will determine the resulting methodology.

\section{STATE OF THE PROJECT AT ITS FIRST MILESTONE}

We identified seven models, theories, or frameworks from Carroll (2003) as potentially useful in enhancing our methodology for tackling critical systems. While Carroll's book is not specific to critical systems, it does cover $\mathrm{HCl}$ in general. These models are: Ethnomethodology (ETHNO), Distributed Cognition (DC), Human Decisionmaking - stress and error (HDM), Mental Models (MM), 


\section{Design rationale MTFs Lingua franca} Hypotheses

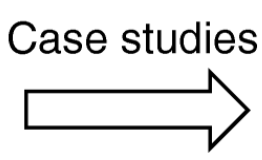

Validation

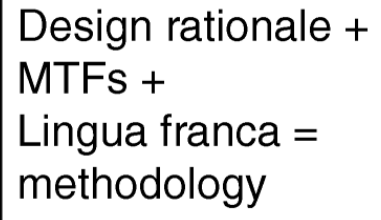
a new methodology.

Cognitive Work Analysis/Ecological Interface Design (CWA/EID), Human Visual Perception (PERC), and Motor Behaviour Models (MOTOR). They can be classified according to the type of design justifications they provide: local (design-related) or global (analysis-based).

Local justifications concern one particular aspect of a design, e.g. the placement of widgets on a screen, or particular visual features (colour, size) of an interface element. These drivers can be found rather easily in the literature, covering problems such as motor behaviour models and human visual processing.

In other cases, design decisions need to be driven by information collected during activities occurring before the actual design, e.g. field studies or domain analyses. It could also be that features of the application justify the use of specialist theories and methods. For example, if the critical system requires coordinated efforts from various individuals, then the theory of distributed cognition is highly informative. Similarly, the Cognitive Work Analysis approach is specifically developed for complex sociotechnical systems: applications where human operators control a complex physical process. In those cases, a justification of a design decision is more global since it requires the connection among different types of information arising along the trajectory of UCD. An overview of selected research models found in Figure 2 shows how the topics relate to each other in terms of this global/local dimension and to which phase of the design process they belong. Note that the topics that relate to the whole design process (HDM, MM, CWA/ EID) are positioned on the middle of the $X$ axis.

\section{FINDINGS FROM THE LITERATURE REVIEW: HYPOTHESES}

Our hypotheses, drawn from investigating the topics listed above, can be summarized as follows:

\section{Distributed Cognition (DC): The Resources Model} (Wright et al., 2000) can be used as a framework to analyze and evaluate interaction types, taking into account the insights of distributed cognition. Using this model, we can compare design alternatives on the cognitive effort required from the user.
2. Ethnomethodology (ETHNO): Patterns of cooperative interaction (Martin \& Sommerville, 2004) provide a means to generalize and reuse findings from previous ethnomethodological studies and to organize and classify our own observations. They also inform the requirements engineering and design process.

3. Cognitive Work Analysis/Ecological Interface Design (CWA/EID): A functionoriented, hierarchically structured analysis of the system helps to determine what information needs to be displayed so that users can make informed decisions, even in unanticipated situations, as stated by Burns and Hajdukiewicz (2004). This topic relates to the concepts of situation awareness and reduction of cognitive effort.

4. Mental Models (MM): Mental models are a useful construct for the design of critical systems, where (designed) target mental models are distinct from (emerging) individual mental models. For the elicitation of individual mental models many methods are available, among which are teachback, developed by Johnson and Johnson (1987), joint exploration, and others akin to task analysis. No representational (visual) framework for mental models stands out. A multi-layered, multi-center framework appears necessary to cater to the complexity of critical systems.

5. Motor behaviour models (MOTOR) describe or predict aspects of a user's physical interaction with a computer. This topic belongs to the domain of (physical) ergonomics. We studied the most relevant literature on principles for human action (Accot \& Zhai, 1997; Fitts, 1954; Guiard, 1987; Smith, 1996) and concluded that these laws are not only applicable in the design of critical systems, but need to be respected in all types of interaction design.Consequently, motor behaviour models will not result in new kinds of design methods; it is only a matter of respecting the specified principles. Therefore, we decided neither to further investigate this domain in the current project nor 


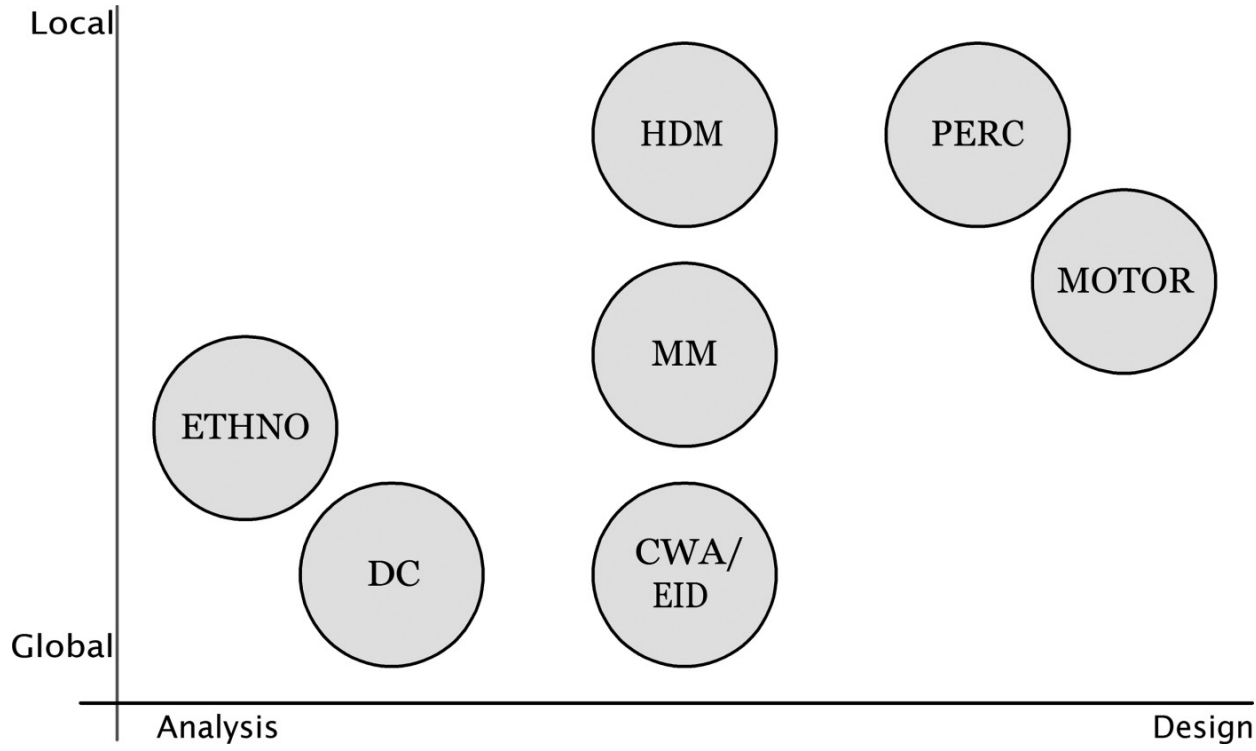

to formulate hypotheses from a methodological perspective.

6. Human visual perception (PERC): Some general, well-known principles apply rather to the early vision stages than to the actual interpretation of objects as demonstrated by Ware $(2003,2004)$. It would be most interesting to relate these to lowering the cognitive load of the user in complex applications. More specific aspects of visual perception, related to the domain of radiology investigated by Krupinsky (2006) and Krupinsky et al. (2003) may be combined with these general principles to form design guidelines for this particular type of medical application.

7. Human Decision Making and Error (HDM): We approach this MTF in a system-oriented way. This implies that we do not focus on who made the error, but on how and why the defenses failed, and what factors contributed to the conditions that led to the error. Naturalistic decision-making, as argued by Zsambok and Klein (1997), emphasizes the importance of experience and situation awareness to prevent errors.

\section{FINDINGS FROM THE LITERATURE REVIEW: IMPORTANT CONCEPTS}

A number of concepts emerged across the different topics that seem to be crucial to the notion of critical systems. They are useful in shaping our view, including our ontology of critical systems, and in connecting hypotheses from different topics. Moreover, they may be integrated in our lingua franca, which will improve communication between researchers and practitioners.

Examples of concepts are situation awareness, cognitive stability, reduction of cognitive effort, and system vs. human reliability. As part of our effort to develop a lingua
Figure 2.

Overview of selected research models, theories and frameworks (MTFs), which shows the coverage of the MTFs in terms of overall project approach. franca, we are developing a conceptual map relating the different types of concepts.

\section{METHODOLOGICAL FINDINGS}

Although our work on methodology is planned in Phase 3 of the project, we have already obtained some preliminary findings as a result of our work in Phase 1.

Lingua Franca: Design patterns that encapsulate best practices are instrumental in establishing the link between research and practice. Following Mahemoff and Johnston (2001) and Mahemoff (2001) we are interested in patterns that are in the scope of critical systems and form a set of interdependent building blocks.

Design Rationale (DR): Whereas the different formalisms and tools for performing design rationale tend to merge, it seems to be more important to distinguish liability issues (cf. risk assessment) from the methodological perspective of DR. The main purpose and focus when performing $\mathrm{DR}$ is rather to promote a research attitude that reuses earlier techniques.

Risk Assessment: During Phase 1 we discovered a relevant new MTF concerning risk assessment as described by Johnson (2006). A risk-led approach involves investigating what went wrong in the past, when using tools similar to the one under development, what might go wrong in the future with the device under development, how one might rank these risks according to their potential impact, and how to distribute the design efforts according to this ranking. This topic is to become a cornerstone element of our new methodology.

\section{WHAT'S NEXT?}

Phase 2 of the project is dedicated to validating the hypotheses resulting from our literature review. The 


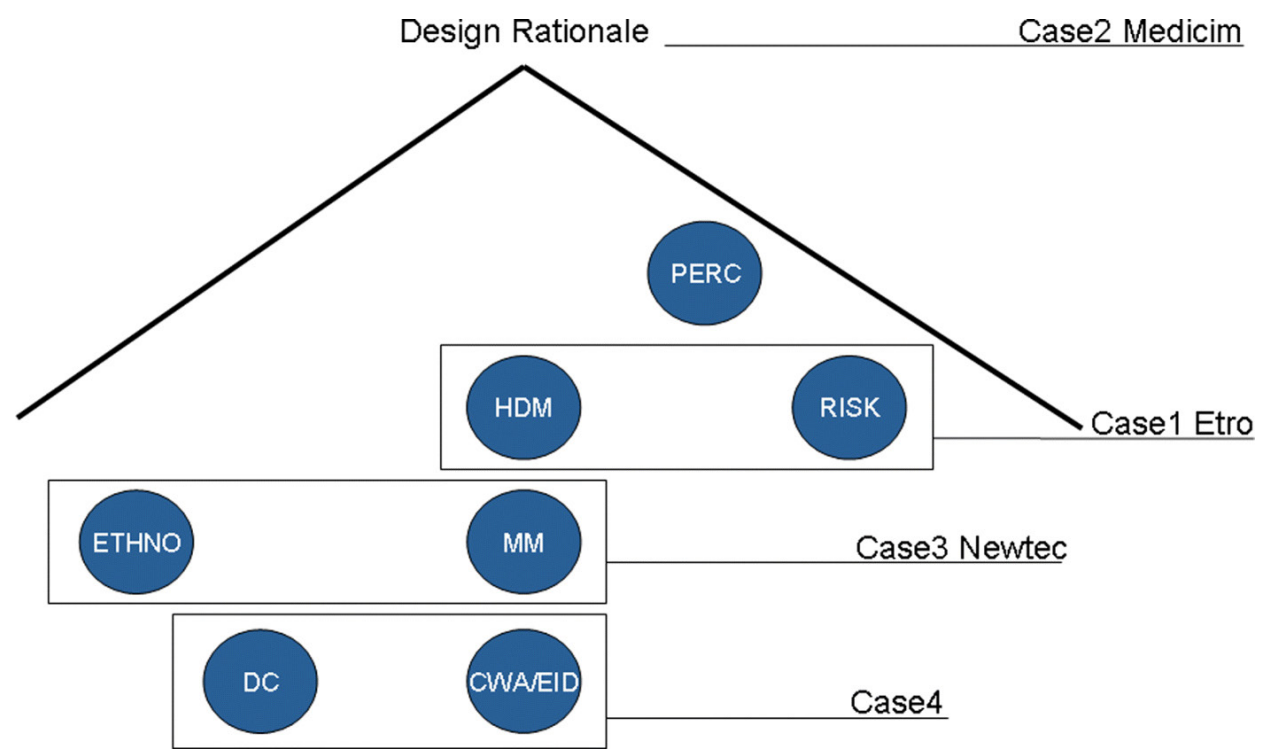

Figure 3.

Validating hypotheses in case studies, which shows the pairwise validation of hypotheses in case studies. diagram in Figure 3 provides an overview of what hypotheses will be tackled in the case studies.

\section{THE CASES \\ ETRO}

In cooperation with the University Hospital Brussels (UZB) and ETRO, an engineering department of the VUB (Vrije Universiteit Brussel), this case study focuses on developing novel interface concepts for radiology device tools for liver cancer diagnosis. The hypotheses below will be validated.

Human Decision Making (HDM): The common types of error in medical imaging application will be defined. In conformance with the system-oriented approach, we aim to identify possible faults in an application, being part of the user and task analysis. Three particular methods will be investigated: TAFEI, SHERPA and EHTA. Because the conditions contributing to errors will be scrutinized, insight into these triggers will facilitate the exploration of interface and interaction solutions for the prevention of, or defense against, errors.

RISK: We will validate FMEA (Failure Mode and Effects Analysis) as a method for assessing potential safety failures in the interface design. GSN (Goal Structured Notation) will be validated as a method for formulating structured, rigorous and clear arguments that a system is acceptably safe to operate in a given context.

\section{Medicim}

This case study concerns preoperative planning for maxillofacial surgery. We redesigned a wizardlike module to map pictures of patients on a threedimensional surface of a face. The existing interface of the tool implements a time-consuming process that often yields very poor results. This leads to often skipping this extra validation step, hence to a greater risk for the surgery.

We validated our hypothesis concerning a design rationale in this case study. As a major outcome, we found that building a design rationale is a valuable technique for validating the design, and, to a lesser extent, for internal and communication about the design process.

\section{Newtec}

This case study focuses on developing Newtec's remote monitoring and control of groundbased satellite telecoms equipment. The topics to be investigated and validated in this case are listed below.

MM: The study's emphasis is on developing an adequate mental model for the device. The teach-back method will be validated and a representational framework decided.

ETHNO (Ethnomethodology): During the extensive field study, the idea of patterns of cooperative interaction will be used. Patterns of cooperative interaction are generalized findings of previous ethnomethodological studies that can be reused. When writing the field study report for the Newtec case, we will try to align the findings with, and structure them by the patterns of cooperative interaction as specified by Martin and Sommerville (2004).

Task analysis: The literature on critical systems recommends performing a task analysis as a part of the design process. We want to take the opportunity now to select a promising task analysis technique, or formalism, and validate whether it is viable and how it should be fine-tuned in the context of critical systems. 
Concept maps: Concept maps are the result of GEM sessions developed by Boy (1997) during which statements or opinions are confronted and elaborated. We expect the field study for this case to deliver rather conflicting visions: technical ones of the design engineers and practical ones of the end-users. To have a clear understanding of this conflict, we want to organize a GEM session and create a concept map based on the results of the GEM session. The concept map in which the concepts discussed are interpreted, explained, and structured will then be used as a basis for the mental model.

\section{Case 4}

The last case study consists of a complex sociotechnical system with time-critical decision- making and equipment under control, such as railway signaling, which is adequate to verify the hypotheses with regard to the following:

- DC (Distributed Cognition): Can we use the Resources Model to compare different design alternatives with regard to the cognitive effort required from the user?

- CWA/EID (Ecological Interface Design): A work domain analysis will provide a different view of the system and help in eliciting the information that needs to be displayed to support situation awareness.

\section{PROJECT OBSTACLES: RESOURCE LIMITATIONS AND BREADTH OF DOMAIN}

In this section, we note some of the obstacles encountered on this project. As a consequence of our deliberate decision to take a distributed approach to the study and implementation of research, we know that the project experiences continuous pressure from day-to-day commercial projects. Designers need to free up time that would otherwise be spent solving the pressing needs of client projects. Thus, the research project must progress with limited resource. Further, even within the selected topics, it is hard to determine which materials are most promising in terms of practical applicability. Finally, our validation phase involves only a limited number of case studies and each hypothesis is validated in only one of these case studies. In none of the cases will we be able to cover both analysis and design activities.

\section{CONCLUSION}

We have presented a project aimed at bridging the gap between the theory and practice of User Centered Design (UCD) within the critical systems domain. Well aware of the challenges and risks, we deliberately opted for a distributed research approach among colleagues in our office, so as to avoid creating a theorypractice gap within our own company. In trying to bridge the gap between theory and practice, we are compelled to first take the perspective of the researchers and to consider $\mathrm{HCl}$ from a more theoretical point of view. Generating hypotheses requires us to interpret research findings in terms of the practice of UCD. Finally, applying new ideas to the case studies gives us insight into the feasibility of newly acquired methodological concepts.

Despite the pressure of commercial projects on the resources for the project, the first phase has delivered interesting hypotheses, which are currently being validated through case studies in the target domain. The outline of our radically new methodology is emerging and we have learned a number of new concepts that broaden our view of $\mathrm{HCl}$, such as situation awareness or reduction of cognitive effort.

As practitioners, Namahn found the excursion into the world of research both exciting and stimulating. Most of our consultants indicated that, if more resources were available, they would gladly further explore the research world. This investigation broadened and deepened our view of the field in which we are working. On the other hand, we had trouble grasping the broad domain within the limitations of resources. The overviews of the field provided by Carroll (2003) and Rogers (2004) are invaluable in that respect. Furthermore, the papers that were most inspiring were those that created a link with UCD practice and suggested the implications of theoretical outcomes for the practice of improving user interface design. We are confident that projects like ours will help advance the dialogue between researchers and practitioners.

\section{ACKNOWLEDGEMENTS}

This project is funded by IWOIB, the Institute Fostering Scientific Research and Innovation of the Brussels Region.

\section{REFERENCES}

Accot, J., \& Zhai, S. (1997). Beyond Fitts' law: Models for trajectory-based $\mathrm{HCl}$ tasks. In S. Pemberton (Ed.), Proceedings of the CHI'97 Conference on Human Factors in Computing Systems (pp. 295-302). New York: ACM.

Boy, G. (1997). The group elicitation method for participatory design and usability testing. Interactions, 4(2), 27-33.

Burns, C. M., \& Hajdukiewicz, J. R. (2004). Ecological interface design. Boca Raton, FL: CRC Press.

Carroll, J.M. (Ed.). (2003). HCl models, theories and frameworks. San Francisco, CA: Morgan Kaufmann.

Collins, J. (2001). Good to great: Why some companies make the leap ... and others don't. New York: HarperBusiness. 
Fitts, P. M. (1954). The information capacity of the human motor system in controlling the amplitude of movement. Journal of Experimental Psychology, 47, 381-391.

Green, T. R. G., \& Blackwell, A. F. (1998). Design for usability using cognitive dimensions. Tutorial session at British Computer Society conference on Human Computer Interaction HCI'98. Retrieved October 24, 2007 from http:// www.cl.cam.ac.uk/afb21/Cognitive Dimensions/CDtutorial. $\mathrm{pdf}$ (current revisions are maintained online).

Guiard, Y. (1987). Asymmetric division of labor in human skilled bimanual action: The kinematic chain as a model. Journal of Motor Behavior, 19, 486-517.

Johnson, C. W. (2006). Understanding the interaction between safety management and the "can do" attitude in air traffic management: Modeling the causes of the Ueberlingen midair collision. In F. Reuzeau \& K. Corker (Eds.), Proceedings of HumanComputer Interaction in Aerospace 2006. Seattle, WA, USA, 20-22, 105-113. Toulouse, France: Eurisco.

Johnson, L., \& Johnson, N. E. (1987). Knowledge elicitation involving teachback interviewing. In A.L. Kidd (Ed.), Knowledge acquisition for expert systems: A practical handbook. New York: Plenum Press.

Kim, A. C., \& Mauborgne, R. (2005). Blue ocean strategy: How to create uncontested market space and make competition irrelevant. Cambridge, MA: Harvard Business School Press.

Krupinsky, E. A. (2006). The digital reading room and its impact on the radiologist. Business Briefing: Future Directions in Imaging (pp. 1-4).

Krupinsky, E. A., Berger, W., Dalals, W., \& Roehrig, H. (2003). Searching for nodules: What features attract attention and influence detection? Academic Radiology, 10, 861-868.

Martin, D., \& Sommerville, I. (2004). Patterns of cooperative interaction: Linking ethnomethodology and design. ACM Transactions on Computer-Human Interaction, 11(1), 59-89.

Mahemoff, M. (2001). Design reuse in $\mathrm{HCl}$ and software engineering. Unpublished doctoral dissertation, University of Melbourne, Department of Computer Science and Software Engineering, Australia.

Mahemoff, M., \& Johnston, L. J. (2001). Usability pattern languages: The "language" aspect. In M. Hirose (Ed.), Proceedings of Human Computer Interaction: Interact '01 (pp. 350-358). Amsterdam: IOS Press.

Rogers, Y. (2004). New theoretical approaches for human computer interaction. Annual Review of Information Science and Technology, 38, 97-143.

Smith, W. J. (1996). ISO and ANSI ergonomic standards for computer products: A guide to implementation and compliance. Upper Saddle River, NJ: Prentice Hall.

Ware, C. (2003). Design as applied perception. In J. M. Carroll (Ed.), $\mathrm{HCl}$ models, theories and frameworks. San Francisco, CA: Morgan Kaufmann.

Ware, C. (2004). Information visualization. San Francisco, CA: Morgan Kaufman.

Wright, P. C., Fields, R. D., \& Harrison, M. D. (2000). Analyzing humancomputer interaction as distributed cognition: The resources model. Human-Computer Interaction, 15(1), 1-42.

Zsambok, C. E., \& Klein, G. (Eds.). (1997). Naturalistic decision making. Mahwah, NJ: Lawrence Erlbaum Associates.

\section{CORRESPONDENCE}

Sabine Geldof/Joannes Vandermeulen, Namahn,

Grensstraat 21,

BE-1210 Brussels,

Belgium.

E-mail:sg@namahn.com or jv@namahn.com

ISSN 1749-3463 print/ ISSN 1749-3471

DOI: 10.1080/17493460701800181

(C) 2007 Artifact 